\title{
VIBRATION-ASSISTED LASER SURFACE TEXTURING AND ELECTROMACHINING FOR THE INTENSIFICATION OF BOILING HEAT TRANSFER IN A MINICHANNEL
}

\begin{abstract}
The paper describes applications of the vibration-assisted laser surface texturing and spark erosion process as methods of modifying properties and structures of metal surfaces. Practical aspects of the use of produced surfaces in the heat exchanger with a minichannel have been described. Compared with smooth surfaces, developed metal surfaces obtained by vibration-assisted laser surface texturing and electromachining show more effective heat transfer. The local heat transfer coefficient for the saturated boiling region obtained for developed surfaces had the values significantly higher than those obtained for the smooth plate at the same heat flux. The experimental results are presented as the heated plate temperature (obtained from infrared thermography) and relationships between the heat transfer coefficient and the distance along the length of the minichannel for the saturated boiling region.

Keywords: developed surface, vibration laser texturing, electromachining, heat transfer enhancement, minichannel
\end{abstract}

\section{Introduction}

Surface texturing of metal surfaces has become an important issue in metal production and its applications. Many devices with texturing-modified surfaces have shown improved efficiency. Improved heat transfer on a developed surface allows more effective heat transfer. In order to increase the heat transfer coefficient corresponding to the heat transfer enhancement, various passive or active methods of surface modification are used. Extensive research on passive methods shows that modifying the characteristics and structure of the heat transfer surface results in higher energy-efficiency and material savings. Many techniques of heat transfer passive enhancement exist. The properties and structure of a heated surface can be modified using chemical, thermal, mechanical or combined mechanical and thermal processes. The thermal processes include plasma spraying, electric arc spraying, sintering, laser surface texturing or electromachining (spark erosion). The most common mechanical processes are surface rouguhening, texturing, finning, microfinning, depositing porous materials, coating, knurling and complex systems. Active methods use surface vibrations or electric field and atomized cooling liquid spray. Thermal processes, such as laser surface texturing and electromachining, have been used to process the surfaces of heat exchangers [1-13]. The author of [13] reports the preliminary evaluation of heat transfer capability of metal surfaces textured by using laser-vibration melting. The study focuses on the effect of laser power and the laser scanning velocity at steady frequency of circular vibrations on pool boiling heat transfer coefficient for water. In [14] the influence of the laser treatment process on the properties of electro-spark deposited coatings was discussed. In $[15,16]$ porous surfaces with sintering of copper layers were used in research on flow boiling heat transfer in minichannels. Many studies have been conducted on heat transfer in conventional sizes, mini- and microchannels and other confined spaces as face seals $[17,18]$. The increase in heat transfer enhancement resulting from producing micro- or mini-recesses on the heated surface has been found to correspond to the increase in the number of nucleation sites. The presence of the recesses also contributes to an increase in the surface-tovolume ratio, as reported by [6-8].

Issues related to the use of nanofluids are currently being studied by reason of their potential for increasing heat transfer intensity. During nanofluid boiling heat transfer, the nanoparticles deposited on the heating surface can increase the active cavities of nucleate boiling, thereby enhancing boiling heat transfer. Cieslinski reports the results of the investigations of heat transfer during pool boiling of water- $\mathrm{Al}_{2} \mathrm{O}_{3}$, water- $\mathrm{TiO}_{2}$ and water-Cu nanofluids [19] and $\mathrm{SiO}_{2}$ nanoparticles as nanofluid with ethylene glycol and water as a base fluid [20]. The addition of nanoparticles can result in the reduction of an overall heat transfer coefficient for the selected plate heat exchanger [21]. Flow boiling heat transfer with various nanofluids is discussed in [22-25], where [23,25], focus on convective flow flow boiling heat transfer in minichannels, and [24] on the experimental investigation of heat transfer characteristics of the developed laminar flow. 


\section{Characteristics of the vibration-assisted laser surface texturing method}

Laser texturing is a process in the group of surface engineering techniques known as laser micromachining applied when the processed areas are the order of micrometres or millimetres by removing the material using the laser beam energy. Laser texturing process is often applied when high measurement accuracy is required or high endurance materials are involved. The material is processed to achieve the required geometry and/or distribution of properties. The aspect of beam pulse time is essential in laser micro processing because, depending on radiation intensity and exposure time, various mechanisms of impact on the metal occur. The size of the heat zone depends on pulse duration. Long pulse treatment often leaves visible traces of melting and other changes resulting from the heat impact [26]. The laser texturing technique was improved by adding vibration while functionalizing the developed surface. This is a new method of laser surface texturing, proposed and discussed in [27].

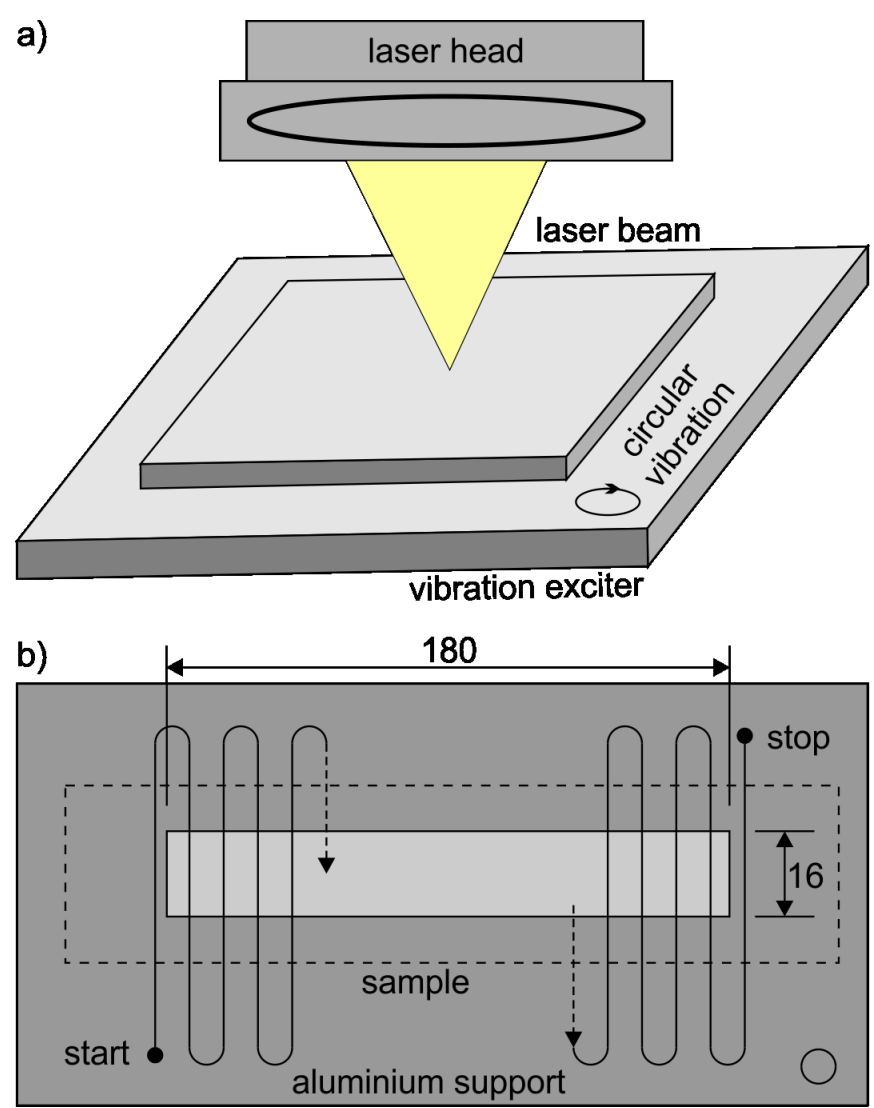

Fig. 1. a) Schematic diagram of the vibration-laser stand, b) schematic diagram of the laser head trajectory

The schematic diagram of the experimental set-up used for vibration-assisted laser texturing is shown in Fig. 1a. The study used the $\mathrm{CO}_{2}$ Trumpf Lasercell 1005 and the laser/cutting head with a $200 \mathrm{~mm}$ focal length, owned by the Centre for Laser Technologies of Metals, Kielce University of Technology. To generate circular vibration with $104 \mathrm{~Hz}$ frequency and $3.5 \mathrm{~mm}$ vibration diameter in the plane perpendicular to the laser beam axis, the eccentric actuator designed especially for this purpose was used. Two rectangular $320 \mathrm{~mm} \times 30 \mathrm{~mm}$ specimens for thermal testing were cut out of the $0.65 \mathrm{~mm}$ thick Hastelloy $\mathrm{X}$ sheet. The specimen for laser texturing was placed under the aluminium matrix with an $180 \mathrm{~mm} \times 16 \mathrm{~mm}$ window drilled in it. The matrix allowed manufacturing of vibration-assisted melts at an exactly specified spot on the specimen surface. The texturing process followed the programmed trajectory of the laser head movement (Fig. 1b), with the following processing parameters: laser power of $2500 \mathrm{~W}$, scanning velocity of $4 \mathrm{~m} / \mathrm{min}$, and argon blow intensity of $10 \mathrm{l} / \mathrm{min}$. The distance between the laser beam paths was $2.5 \mathrm{~mm}$. 3D topography of a fragment of the melts is shown in Fig. 2a and the photo of the fragment - in Fig. 2c. Figure $2 \mathrm{~b}$ shows a profilogram of a fragment of the single path surface, measured using the Taylor Hobson CCI to ISO 251782:2012 (the profilometer scanned the $4.25 \mathrm{~mm} \times 4.25 \mathrm{~mm}$ area).

In the melting area of the $180 \mathrm{~mm} \times 16 \mathrm{~mm}$ specimen, 36 laser paths were obtained, each of $3.8 \mathrm{~mm}$ in width located
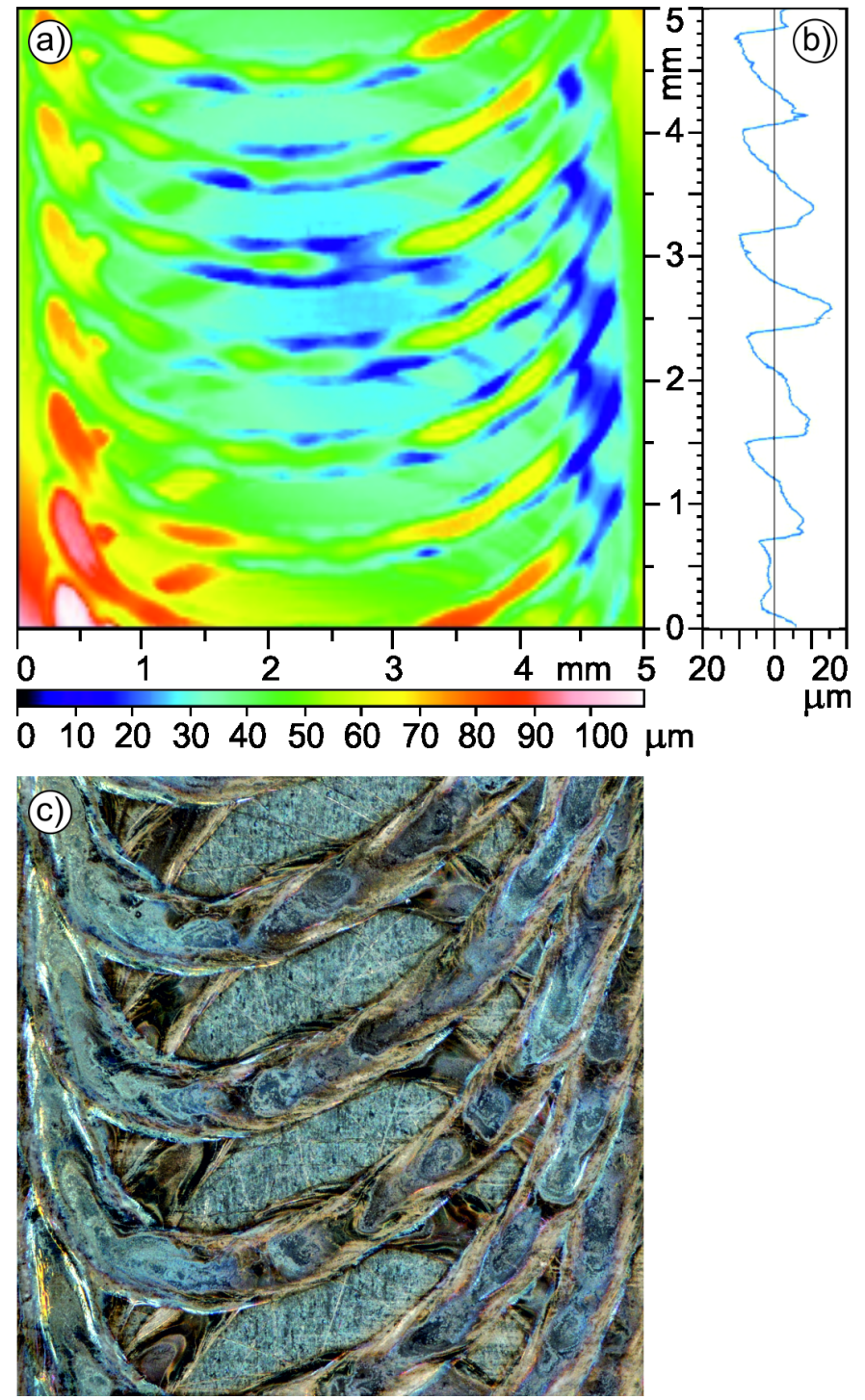

Fig. 2. Plate surface developed by vibration-assisted laser surface texturing: a) topography of a fragment of the melts; b) profilogram of the fragment of a single laser path; c) photo of a fragment of the melts; a,c) magnification of $20 x$ 
about $1.7 \mathrm{~mm}$ apart. The paths had regular melts in the shape of arches about $1 \mathrm{~mm}$ apart in the laser path plane of symmetry. The melts had various solidified structures with multiple dimples and bulges of absolute values in excess of $25 \mu \mathrm{m}$.

\section{Characteristics of electromachining process}

During the spark erosion process in electromachining, the eroded material from the anode is transferred to the cathode, covering its surface with the pure anode material or a layer created by the mutual impact between the electrodes and the medium between them (usually air). The intensity of this transfer depends on the energy contained in the pulse. The electron beam hits the surface and causes rapid heating of the material. High temperature gradient changes the structure of the material producing craters, grooves or irregular cavities. In the pulse discharge, a plasma zone in the spark area, which reaches a high temperature very fast and causes rapid spot melting of the material. The evaporation of the material due to high temperature results in the formation of gas bubbles. High pressure that accompanies the process leads to the explosion of the bubbles and formation of craters or other irregular structures from the melted material. A rapid decrease in temperature that follows makes fraction of the eroded particles solidify on the edges of the crater, while remaining particles are removed by subsequent washing. If a series of pulses is applied, the treated area shows various levels of resultant changes. When a spark erosion machine, i.e. electric-etcher or branding-pen (arcograph) is used, such parameters as the feed and the size of the erosion gap are changed. Any physical disturbance in the erosion gap or changing the feed of the pen reduces energy of the active pulse, which generates geometrically uneven craters with many areas as potential nucleation centres for boiling [26].

Cavities in a plate surface made of Haynes-230 alloy ( $0.45 \mathrm{~mm}$ depth) were made by electromachining using manually controlled electric-etcher and branding-pen. The image of typical cavities obtained in a plate section is presented in Fig. 3a. The $3 \mathrm{D}$ photo of a single cavity is shown in Fig. 3b. An example of the cavity cross-sections (profilogram) from electromachining is shown in Fig. 3c as a representative piece of developed plate (cavities were irregular). The layer of melted metal of the plate and electrode material, reaching locally $5 \mu \mathrm{m}$, accumulates around the recesses. The depth of the cavity craters is usually below $2 \mu \mathrm{m}$.

\section{The measurement module - a heat exchanger with a minichannel}

The study was carried out for a flow boiling process by using the experimental setup shown in Fig. 4. The setup comprises the main loop with working fluid - Fluorinert FC-72, the data and image acquisition system, the supply and control system, and the lighting system. The main loop consists of a heat exchanger, a compensating tank, a gear pump, a mass flowmeter, a filter and
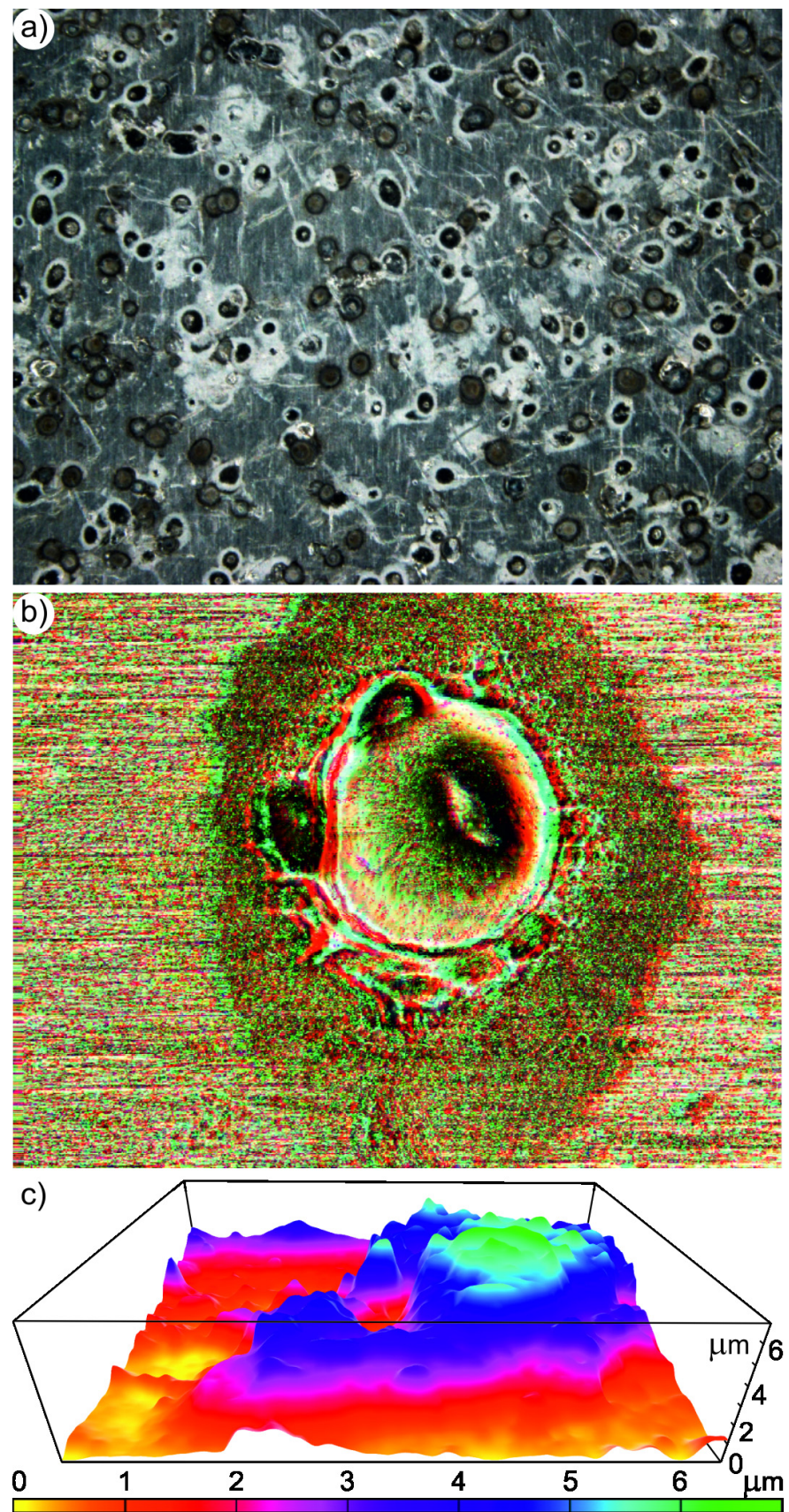

Fig. 3. Plate surface developed by electromachining (spark erosion): a) image of the fragment with cavities, magnification of $10 x$; b) 3D photo of a single cavity, magnification of 200x; c) example cross-section of the cavities (profilogram)

a deaerator. The lighting system comprises high power LEDs $(400 \mathrm{~W})$ to provide light for the two-phase flow. The data and image acquisition system, designed to collect the measurement data, includes a data acquisition station with a computer and appropriate software, an infrared camera E60 FLIR and a digital SLR camera. Thermal accuracy of the Flir E60 camera is $\pm 2^{\circ} \mathrm{C}$ or $\pm 2 \%$ according to the specification data published by the manufacturer. This camera has an additional certificate confirming its higher accuracy of $\pm 1^{\circ} \mathrm{C}$ or $\pm 1 \%$ within the temperature range of $0-120^{\circ} \mathrm{C}[28]$.

The supply and control system consists of an inverter welder, a shunt, an ammeter and a voltmeter. 


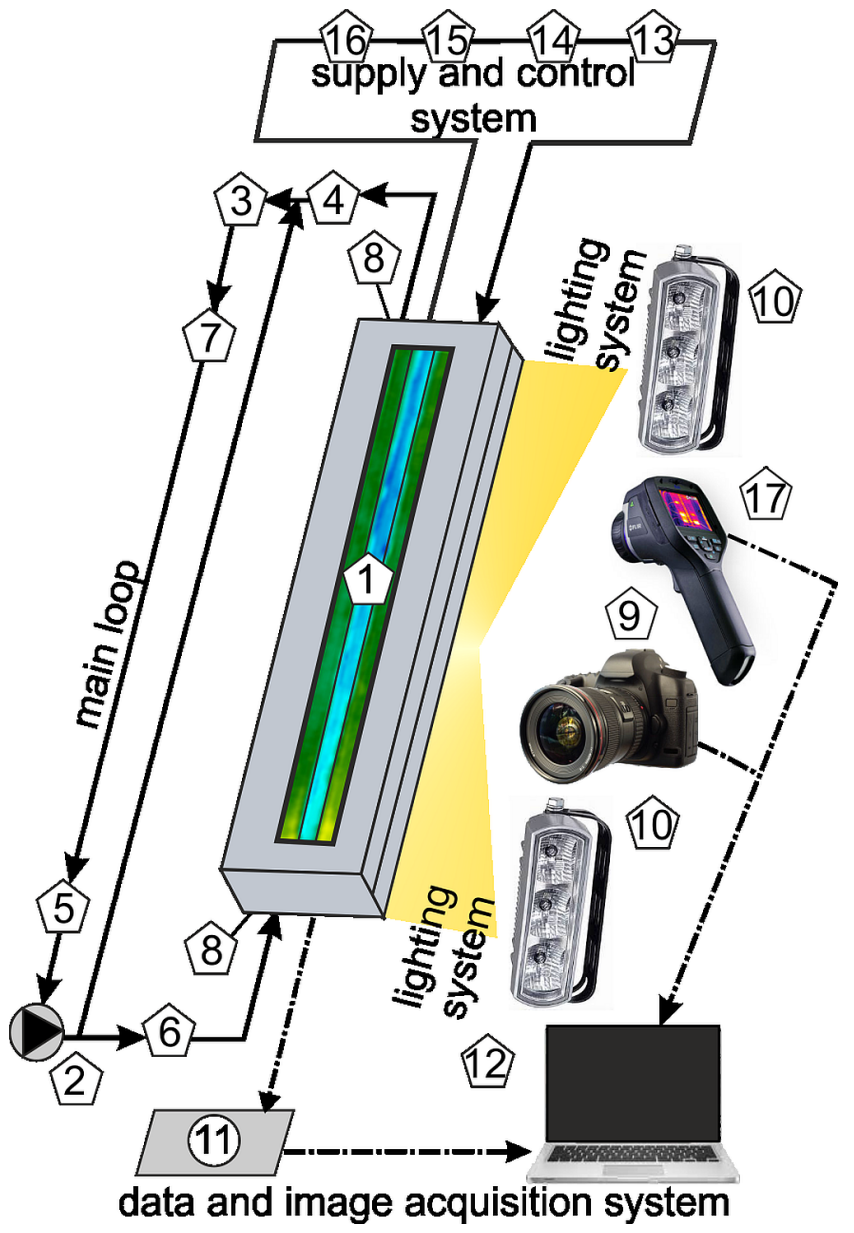

Fig. 4. The schematic diagram of the main systems of the experimental setup, 1 - test section with a minichannel; 2 - gear pump, 3 - compensating tank/pressure regulator, 4 - tube-type heat exchanger, 5 - filters, 6 - mass flowmeter, 7 - deaerators, 8 - pressure converter, 9 - digital SLR camera, 10 - high power LEDs $(400 \mathrm{~W}), 11$ - data acquisition station, 12 - computer pc, 13 - inverter welder, 14 - shunt, 15 - ammeter, 16 - voltmeter, 17 - infrared camera

The essential part of the experimental stand is a vertically oriented rectangular minichannel with a heated plate modified on one side. The schematic diagrams of the test section are shown in Fig. 5.

The minichannel (1) is $1.7 \mathrm{~mm}$ deep, $16 \mathrm{~mm}$ wide, and $180 \mathrm{~mm}$ long. The heated element (2) for FC-72 flowing in the minichannel (1) is a Hastelloy X alloy plate (about $0.65 \mathrm{~mm}$ thick) or a Haynes-230 alloy plate (about $0.45 \mathrm{~mm}$ thick), both manufactured by Haynes Int. Inc. (USA). These materials were chosen for their values of electrical resistivity, assuming minor resistivity changes with temperature. The Hastelloy $\mathrm{X}$ and Haynes-230 alloy plates are made mainly of Ni-Cr-Fe-Mo and Ni-Cr-W-Mo alloys, respectively [29]. In addition to excellent high-temperature strength and oxidation resistance these alloys exhibit superior long-term stability and good fabricability. with multiple dimples and bulges of absolute values in excess of $25 \mu \mathrm{m}$.

In the analyzed experimental series, three different plates were used separately: one plate smooth on both sides and two other plates whose surfaces (in direct contact with the fluid flowing in the channel) were modified either through vibration-

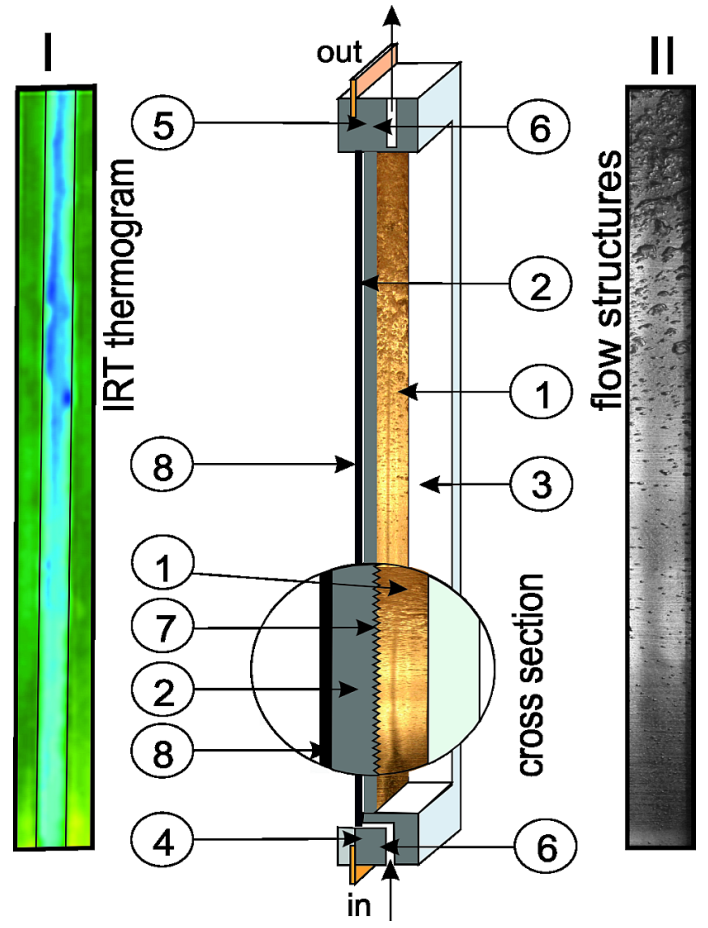

Fig. 5. The schematic diagrams of the test section with the minichannel: 1 - minichannel, 2 - heated plate, 3 - glass panel, 4 - channel body, 5 - front cover, 6 - thermocouple, 7 - enhanced surface of the plate, 8 - black paint layer, I - IRT thermogram, II - two-phase flow structure image

assisted laser surface texturing or by the electromachining process (described above). Roughness parameter of these surfaces were: enhanced surface modified by vibration-assisted laser surface texturing $R a=1.46 \mu \mathrm{m}$ and obtained by electromachining process $R a=0.61 \mu \mathrm{m}$, for the smooth plate $R a=0.18 \mu \mathrm{m}$. Data were obtained by Form Talysurf PGI-1200 measurement system manufactured by Taylor Hobson. The study was conducted in Geometric Computer Measurement Laboratory at the Kielce University of Technology.

The temperature of the smooth sides of the heated plates was measured by infrared thermography (IRT) in the central axially symmetric part of the minichannel (I, Fig. 5). The plates were coated with a black paint (8) with emissivity of about 0.83 [30]. Two-phase flow structures (II) were observed concurrently through the glass panel (3) at the modified side of the plate being in contact with the fluid (7). At the inlet and outlet of the minichannel, pressure converters and K-type thermocouples were installed.

\section{Experiment}

During the experimental series, there was a gradual increase in the electric power supplied to the heated plate followed by an increase in the heat flux transferred to the fluid in the minichannel. This leads to the onset of nucleate boiling and the heat transfer enhancement. The first region after the onset of boiling was the subcooled boiling region - the liquid became 
superheated only in the vicinity of the heated surface but in the core of the flow, it was highly subcooled. The next boiling region was the saturated boiling region. In this region, the temperature of the fluid in the core of the flow was equal to the saturation temperature.

Additional data concerning main experimental parameters: absolute pressures at the inlet to the minichannel, pressure drops from the inlet to the outlet, voltage drops across the plates, current supplied to the plates and heat flux densities are detailed in Table 1.

\section{Measurement uncertainties}

The maximum error for the mass flow measured with a Promass 80A04 mass flowmeter (Endress+Hauser) constituted $0.15 \%$ of the full scale reading and was estimated to be $0.675 \mathrm{~kg} / \mathrm{h}$.

The pressure of the fluid at the inlet and outlet of the minichannels was measured by Endress+Hauser PMP51 Cerabar $\mathrm{M}$ pressure converters. The value registered with accuracy of $\pm 0.05 \%$ of the full scale was $5 \times 10^{-3}$ bar. The error for the fluid temperature was calculated as an error of temperature from the thermoelements placed at the inlet and outlet of the minichannels. This error includes the errors resulting from signal processing by the acquisition cards in the measurement data acquisition system and the thermocouple sensor errors. It was estimated to be $0.77 \mathrm{~K}$ [31-32].

The current supplied to the heated plates was measured indirectly through a shunt $(400 \mathrm{~A}, 60 \mathrm{mV}$ ) cooperating with a digital minivoltmeter. The accuracy class of the shunt is $0.5 \%$, which at its maximum range of $400 \mathrm{~A}$ gives an error of $2 \mathrm{~A}$. The accuracy class of the V-629 digital meter manufactured by Meratronik is $0.1 \%$. The absolute error of current measurement has the resulting value of approx. 2 A [33].

The absolute error of voltage drop measurement is affected by the error resulting from the accuracy class of the BM811 multimeter by Brymer. The accuracy class of this meter is $0.08 \%$, which at its maximum range of $50 \mathrm{~V}$, as used in the measurements, yields an error of $0.04 \pm 0.01 \mathrm{~V}$, according to data from its manufacturer.

The average uncertainties of the heat flux density and the heat transfer coefficient are summarized in Table 2.

The average loss of heat to the surroundings for the analyzed measurement series was $1.3 \%$ of the heat flux density. The greatest heat loss occurred at the highest heat flux, while the smallest was observed at the minimum heat flux [30].

During the experiments, LED light was switched on only for the period of taking photographs, thus the negligibly small effect of lighting on the heat flux was skipped.

\section{Local heat transfer coefficient calculations}

The authors of [12,30,32-36] present various methods of determining the local heat transfer coefficient in the twodimensional approaches employing Trefftz functions obtained from solving the inverse problem. Here, one-dimensional approach is used, taking into account the heat flow direction, which is perpendicular to the direction of the fluid flow in the minichannel. The calculations took into account only the data obtained for the saturated boiling region. In the fully developed nucleate boiling, the heat transfer coefficient was the highest but then it decreased sharply with an increase in the distance from the channel inlet. The results for the subcooled boiling region were discussed in previous works.

Local heat transfer coefficients $\alpha(x)$ in the saturated boiling region are determined from the following equation:

$$
\alpha(x)=\frac{q_{w}^{I R T}}{T_{F}(x)-T_{s a t}(x)-q_{w}^{I R T} \cdot \frac{\delta_{F}}{\lambda_{F}}}
$$

where $x$-distance from the minichannel inlet along the direction of the flow, $q_{w}^{I R T}$ - the heat transferred to the fluid in the

TABLE 1

Experimental parameters

\begin{tabular}{|c|c|c|c|c|c|c|}
\hline Surface & $\begin{array}{l}\text { Thickness } \\
\text { [mm] }\end{array}$ & $\begin{array}{c}\text { Absolute pressure at the } \\
\text { channel inlet }[\mathrm{kPa}]\end{array}$ & $\begin{array}{c}\text { Pressure drop } \\
{[\mathrm{kPa}]}\end{array}$ & $\begin{array}{c}\text { Current } \\
I[\mathrm{~A}]\end{array}$ & $\begin{array}{c}\text { Voltage drop } \\
\Delta U[\mathrm{~V}]\end{array}$ & $\begin{array}{c}\text { Heat flux } \\
q_{w}\left[\mathrm{~kW} / \mathrm{m}^{2}\right]\end{array}$ \\
\hline Laser & \multirow{2}{*}{0.65} & \multirow{2}{*}{$135 \div 175$} & \multirow{4}{*}{$9 \div 13$} & \multirow{2}{*}{$190 \div 230$} & \multirow{2}{*}{$3.5 \div 3.9$} & \multirow{2}{*}{$73 \div 103$} \\
\hline Smooth & & & & & & \\
\hline Electromachining & \multirow{2}{*}{0.45} & \multirow{2}{*}{$125 \div 150$} & & \multirow{2}{*}{$140 \div 225$} & \multirow{2}{*}{$3.3 \div 5.0$} & \multirow{2}{*}{$73 \div 98$} \\
\hline Smooth & & & & & & \\
\hline
\end{tabular}

TABLE 2

Average uncertainties of the relative heat flux and the heat transfer coefficient

\begin{tabular}{|c|c|c|c|c|}
\hline \hline \multirow{2}{*}{ Surface } & \multirow{2}{*}{ Thickness $[\mathbf{m m}]$} & \multirow{2}{*}{ Heat flux $\boldsymbol{q}_{\boldsymbol{w}}\left[\mathbf{k W} / \mathbf{m}^{2}\right]$} & \multicolumn{2}{|c|}{ Average uncertainties (relative errors) } \\
\cline { 3 - 5 } & 0.65 & 77.34 & Heat flux $\boldsymbol{q}_{\boldsymbol{w}}[\boldsymbol{\%}]$ & Heat transfer coefficient $\boldsymbol{\alpha}[\boldsymbol{\%}]$ \\
\hline Smooth & 0.65 & 73.31 & 3.04 & 2.88 \\
\hline Laser & 0.45 & 82.37 & 15.06 & 12.70 \\
\hline Smooth & 0.45 & 81.10 & 2.66 & 1.51 \\
\hline Electromachining & \multicolumn{2}{|l}{} & 3.23 & 3.68 \\
\hline
\end{tabular}


minichannel, $T_{F}(x)$ - the plate temperature measured by infrared thermography, $T_{\text {sat }}(x)$ - the saturation temperature determined on the basis of the linear distribution of pressure along the length of the minichannel from the inlet to the outlet, $\lambda_{F}-$ the coefficient of thermal conductivity of the plate, $\delta_{F}-$ the plate thickness.

The heat transferred to the fluid in the minichannel $q_{w}^{I R T}$ is assumed to be equal to the difference between the heat generated by the heated plate and the heat loss to the surroundings [30].

$$
q_{w}^{I R T}=q_{w}-q_{w l o o s}
$$

where: $q_{w}-$ the heat flux generated by the heated plate, $q_{\text {wloos }}-$ heat loss to the surroundings.

The temperatures of the heating surface at the inlet and outlet of each minichannel (about 10\% from each side) were
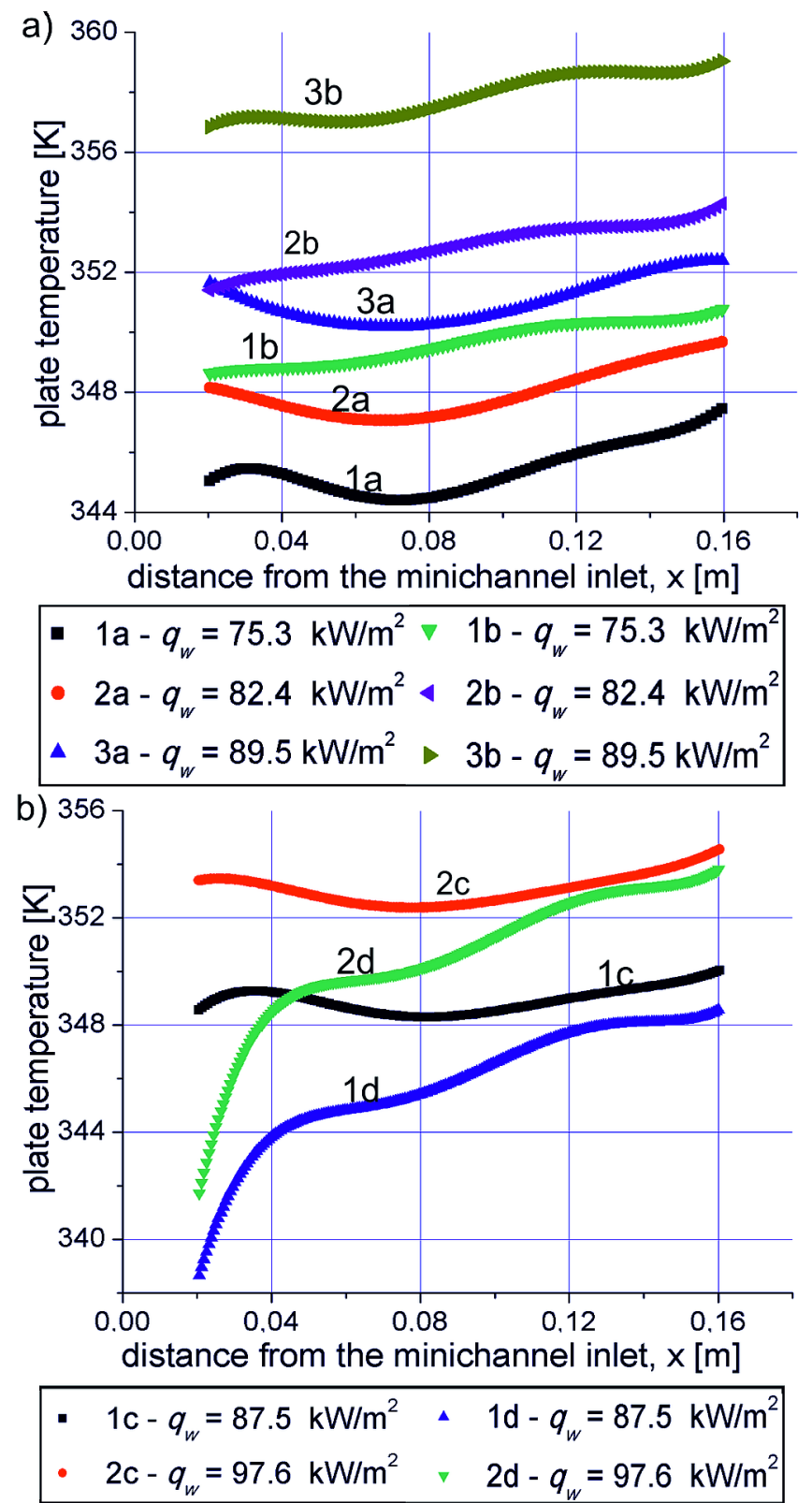

Fig. 6. Heated plate temperature versus the minichannel length, data for: a) the vibration-assisted laser plate texturing (1a-3a) and the smooth plate $(1 b-3 b) ; b)$ the electromachining plate texturing (1d-2d) and the smooth plate (1c-2c) ignored due to the occurrence of the largest measurement errors when using IR thermography, as reported in detail in [37]. The plate temperatures and local heat transfer coefficients for the saturated boiling region were approximated with the 5-degree polynomial.

\section{Results and observations}

The experimental results are presented as the relationship between the heated plate temperature (obtained from IRT) and the distance along the minichannel length for:

- the vibration-assisted laser textured plate (1a-3a) and the smooth plate (1b-3b), Fig. 6a,

- the electromachined plate (1d-2d) and the smooth plate (1c-2c), Fig. 6b.

Local heat transfer coefficients as a function of the distance from the minichannel inlet are presented in Figs. 7 and 8, respectively.

It was observed that the heated plate temperature measured for vibration-assisted laser plate texturing achieved larger values than the smooth plate. The temperature for enhanced surface is higher about $4 \mathrm{~K}$ (1a-1b and $2 \mathrm{a}-2 \mathrm{~b})$ and $8 \mathrm{~K}$ (3a-3b), as shown in Fig. 6a. A similar observation was made while analyzing the data in Fig. 6b, which show that the smooth plate had lower temperature values than the electromachined plate. At the channel inlet, the temperatures of the smooth heated plate were about $10 \mathrm{~K}$ or $4 \mathrm{~K}(2 \mathrm{c}-2 \mathrm{~d})$ higher than those of the electromachined plate (1c-1d). At the channel outlet, the difference between the measured temperatures dropped to about 1-2 K.

The values of local heat transfer coefficient for saturated boiling region obtained for vibration-assisted laser textured plate and electromachined plate were markedly higher in comparison with the smooth plate for the same heat flux, as shown

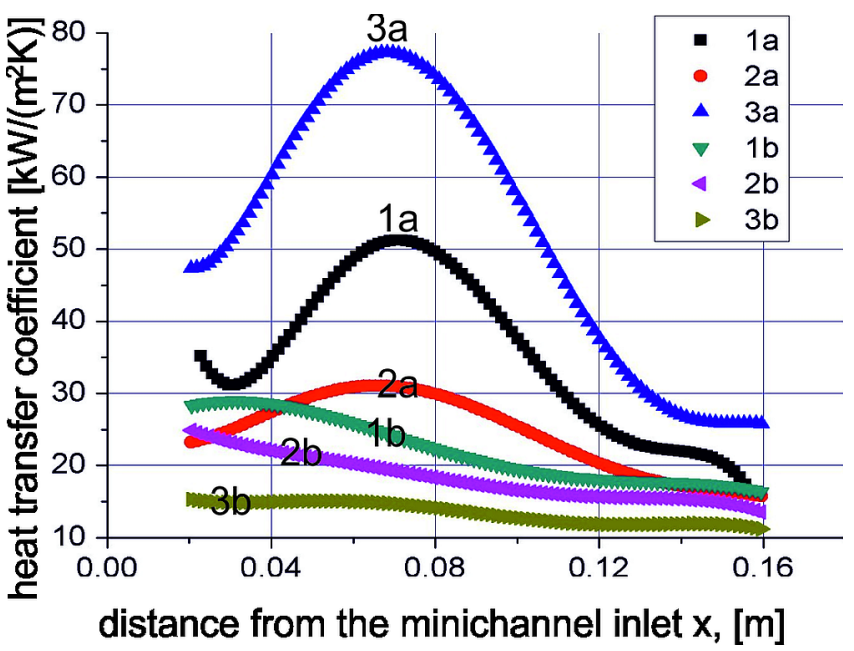

Fig. 7. Heat transfer coefficient versus the minichannel length calculated for the vibration-assisted laser plate texturing (1a-3a) and for the smooth plate (1b-3b), experimental parameters: average mass flux of $407 \mathrm{~kg} /\left(\mathrm{m}^{2} \mathrm{~s}\right)$, average inlet pressure of $143 \mathrm{kPa}$, average inlet liquid subcooling of $41.2 \mathrm{~K}$, heat flux: 1a, 1b) $q_{w}=75.3 \mathrm{~kW} / \mathrm{m}^{2} ; 2 \mathrm{a}, 2 \mathrm{~b}$ ) $\left.q_{w}=82.4 \mathrm{~kW} / \mathrm{m}^{2} ; 3 \mathrm{a}, 3 \mathrm{~b}\right) q_{w}=89.5 \mathrm{~kW} / \mathrm{m}^{2}$ 


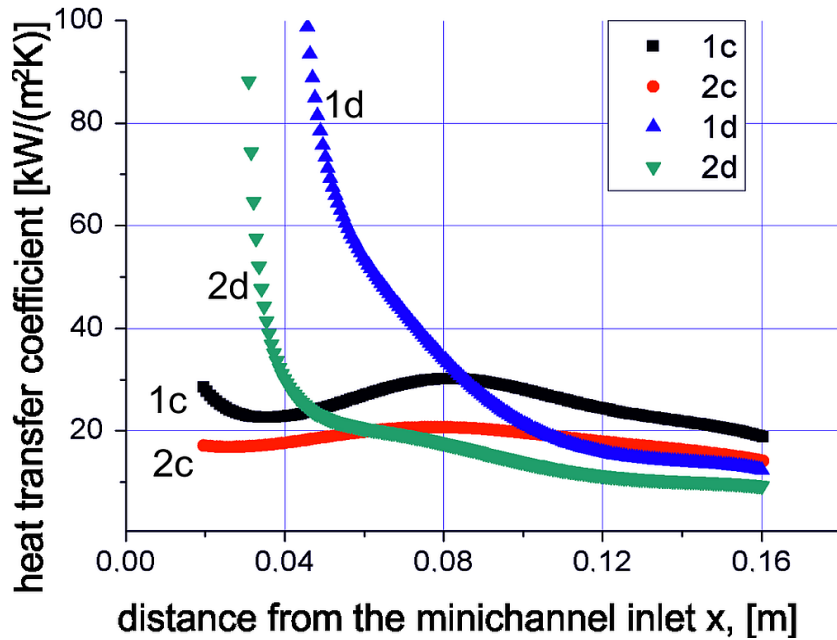

Fig. 8. Heat transfer coefficient versus the minichannel length determined from the one-dimensional model for the electromachined plate (1d-2d) and the smooth plate (1c-2c), experimental parameters: average mass flux of $407 \mathrm{~kg} /\left(\mathrm{m}^{2} \mathrm{~s}\right)$, average inlet pressure of $144 \mathrm{kPa}$, average inlet liquid subcooling of $43.6 \mathrm{~K}$, heat flux: 1c, 1d) $q_{w}=87.5 \mathrm{~kW} / \mathrm{m}^{2}$; 2c, 2d) $q_{w}=97.6 \mathrm{~kW} / \mathrm{m}^{2}$

in Figs. 7 and 8. For vibration-assisted laser surface texturing, the maximum values of local heat transfer coefficient were about $80 \mathrm{~kW} /\left(\mathrm{m}^{2} \mathrm{~K}\right)$. At the inlet channel, the local heat transfer coefficient was increasing to a distance of $0.07 \mathrm{~m}$, then began to decrease on the way to the channel outlet (see Fig. 7). This was probably caused by the structure of the heat dissipating surface. By contrast, the local heat transfer coefficient from the smooth plate was decreasing along the entire distance from the inlet to the outlet of the channel and achieved the maximum of $30 \mathrm{~kW} /\left(\mathrm{m}^{2} \mathrm{~K}\right)$. The values of the local heat transfer coefficient obtained for the electromachined plate were also higher, by approximately $70 \mathrm{~kW} /\left(\mathrm{m}^{2} \mathrm{~K}\right)$ at the channel inlet (see Fig. 8), in comparison with the smooth plate at the same heat flux.

Concluding, the developed heated plates, modified by the vibration-assisted laser surface texturing and electromachining process, reach more effective heat transfer in comparison with the smooth heated surface for the saturated boiling region.

\section{Conclusion}

The article presents the application of the vibration-assisted laser surface texturing and spark erosion process as methods of modifying properties and structures of metal surfaces. Practical aspects of the application of enhanced surfaces in heat transfer research by using them in the measurement module - heat exchanger with a minichannel were emphasized. The local heat transfer coefficient for the saturated boiling region obtained for electromachined plate and laser textured plate achieved values significantly higher that those form smooth plate for the same heat flux. Analysis of the results of this study indicates that the application of enhanced heated metal surfaces allows achieving more effective heat transfer in comparison with the smooth heated plate.

\section{Acknowledgements}

The research reported herein was supported by the grant from the Polish National Science Centre (No. DEC-2013/09/B/ST8/02825).

\section{REFERENCES}

[1] R. Pastuszko, M. Piasecka, Pool boiling on surfaces with mini-fins and micro-cavities, J. Phys. Conf. Ser. 395 (12137), 7 (2012).

[2] R. Pastuszko, Pool boiling on rectangular fins with tunnel-pore structure, EPJ Web of Conferences 45 (01020), 5 (2013).

[3] T. Orzechowski, K. Stokowiec, Quasi-stationary phase change heat transfer on a fin, EPJ Web Conf. 114 (02086), 5 (2016).

[4] N. Radek, Ł.J. Orman, Preliminary data of boiling heat transfer of laser treated heat exchanger surfaces, in: J.I. Shalapko, L.A. Dobrzanski (Eds.), Scientific Basis of Modern Technologies: Experience and Prospects, Khmelnytskyi National University, Jaremche, Ukraine, 236-245 (2011).

[5] L. Dąbek, A. Kapjor, Ł.J. Orman, Ethyl alcohol boiling heat transfer on multilayer meshed surfaces, AIP Conference Proceedings, 1745, 1-5 (2016).

[6] M. Piasecka, Correlations for flow boiling heat transfer in minichannels with various orientations, Int. J. Heat Mass Transf. 81, 114-121 (2015).

[7] M. Piasecka, Impact of selected parameters on refrigerant flow boiling heat transfer and pressure drop in minichannels, Int. J. Refrig. 56, 198-212 (2015).

[8] M. Piasecka, Heat transfer research on enhanced heating surfaces in flow boiling in a minichannel and pool boiling, Ann. Nucl. Energy, 73, 282-293 (2014).

[9] T. Orzechowski, Boiling heat transfer on the fin with laser modified surface, Int. Symp. on Convective Heat and Mass Transfer in Sustainable Energy, April 26-May, Tunisia, 1-14 (2009).

[10] M. Ameli, B. Agnew, P.S. Leung, B. Ng, C.J. Sutcliffe, J. Singh, R. McGlen, A novel method for manufacturing sintered aluminium heat pipes (SAHP), Appl. Therm. Eng. 52 (2), 498-504 (2013).

[11] A.D. Sommers, K.L. Yerkes, Using micro-structural surface features to enhance the convective flow boiling heat transfer of R-134a on aluminum, Int. J. Heat Mass Transf. 64, 1053-1063 (2013).

[12] B. Maciejewska, K. Strąk, M. Piasecka, The solution of a two-dimensional inverse heat transfer problem using the Trefftz method, Procedia Eng. 157, 82-88 (2016).

[13] B. Grabas, Vibration-assisted laser surface texturing of metals as a passive method for heat transfer enhancement, Exp. Therm. Fluid Sci. 68, 499-508 (2015).

[14] N. Radek, B. Antoszewski, The influence of laser treatment on the properties of electro-spark deposited coatings, Kovove Materialy-Metallic Materials 47 (1), 31-38 (2009).

[15] W. Depczyński, Sintering of copper layers with a controlled porous structure, METAL 2014 23rd Int. Conf. Metallurgy and Materials, Ostrava, 1219-1224 (2014).

[16] W. Depczyński, P. Młynarczyk, S. Spadło, E. Ziach, P. Hepner, The selected properties of porous layers formed by pulse micro- 
welding technique, 24th Int. Con. Metallurgy and Materials, Brno, 1087-1092 (2015).

[17] S. Blasiak, J.E. Takosoglu, P.A. Laski, Heat transfer and thermal deformations in non-contacting face seals, J. Therm. Sci. Technol. 9 (2), 1-8 (2014).

[18] S. Blasiak, An analytical approach to heat transfer and thermal distortions in non-contacting face seals, Int. J. Heat Mass Transf. 81, 90-102 (2015).

[19] J. T. Cieśliński, K. Krygier, Influence of surface curvature on sessile droplet contact angle of nanofluids, Trans. Inst. Fluid-Flow Mach. 125, 3-12 (2013).

[20] H. Boertz, A. Baars, J. T. Cieśliński, S. Smolen, Turbulence model evaluation for numerical modelling of turbulent flow and heat transfer of nanofluids, Appl. Mech. Mater. 831, 165-180, (2016).

[21] J.T. Cieśliński, A. Fiuk, B. Siemieńczuk, Performance of a plate heat exchanger operated with water- $\mathrm{Al}_{2} \mathrm{O}_{3}$ nanofluid, Appl. Mech. Mater. 831, 188-197 (2016).

[22] O. S. Prajapati, N. Rohatgi, Flow boiling heat transfer enhancement by using ZnO-water nanofluids, Hindawi Publ. Corp. 2014, 7 pages (2014).

[23] L. Yu, A. Sur, D. Liu, Flow boiling heat transfer and two-phase flow instability of nanofluids in a minichannel, J. Heat Transfer, 137 (051502), 1-11 (2015).

[24] A. Dominic, J. Sarangan, S. Suresh, V.S. Devah Dhanush, An experimental investigation of wavy and straight minichannel heat sinks using water and nanofluids, J. Therm. Sci. Eng. Appl. 7 (3), 9 pages (2015).

[25] A.A. Chehade, H.L. Gualous, S. Le Masson, F. Fardoun, A. Besq, Boiling local heat transfer enhancement in minichannels using nanofluids, Nanoscale Res. Lett. 8, 20 p. (2013).

[26] M. Piasecka, Laser texturing, spark erosion and sanding of the surfaces and their practical applications in heat exchange devices, Adv. Mater. Res. 874, 95-100 (2014).

[27] B. Grabas, Impact of the parameters of laser-vibration treatment on the roughness of aluminium melts, Adv. Mater. Res. 874, 71-75 (2014).
[28] Calibration certificate No. K1501035, Calibration laboratory No. 2372, accredited by Czech ccreditation Institute under ČSN EN ISO/IEC 17025:2005 for: Calibration of non-contact temperature measuring instruments.

[29] www.haynesintl.com.

[30] M. Piasecka, K. Strąk, B. Maciejewska, Calculations of flow boiling heat transfer in a minichannel based on Liquid Crystal and Infrared Thermography data, Heat Transf. Eng. 38 (3), 332-346 (2017).

[31] M. Piasecka, Determination of the Temperature field using Liquid Crystal Thermography and analysis of two-phase flow structures in research on boiling heat transfer in a minichannel, Metrol. Meas. Syst. XX (2), 205-216 (2013).

[32] M. Piasecka, B. Maciejewska, The study of boiling heat transfer in vertically and horizontally oriented rectangular minichannels and the solution to the inverse heat transfer problem with the use of the Beck method and Trefftz functions, Exp. Therm. Fluid Sci. 38, 19-32 (2012).

[33] M. Piasecka, Theoretical and experimental investigations into flow boiling heat transfer in a narrow channel (in Polish), Ph. D. Thesis. Poland: Kielce University of Technology, 2002.

[34] B. Maciejewska, M. Piasecka, Trefftz function-based thermal solution of inverse problem in unsteady-state flow boiling heat transfer in a minichannel, Int. J. Heat Mass Transf. 107, 925-933 (2017).

[35] M. Piasecka, B. Maciejewska, Heat transfer coefficient during flow boiling in a minichannel at variable spatial orientation, Exp. Therm. Fluid Sci. 68, 459-467 (2015).

[36] S. Hożejowska, M. Piasecka, Equalizing calculus in Trefftz method for solving two-dimensional temperature field of FC-72 flowing along the minichannel, Heat Mass Transf. 50 (8), 1053-1063 (2014).

[37] M. Piasecka, D. Michalski, K. Strąk, Comparison of two methods for contactless surface temperature measurement, EPJ Web Conf. 114 (02094), 9 (2016). 